\title{
Generating Positive Orientation in Therapy or Consultation: A Perspective Through an Article Review on Positive Psychology
}

\author{
Mehmet Aslan \\ 'Hëna e Plotë' Beder University \\ Tirana/Albania \\ maslan@beder.edu.al
}

\begin{abstract}
Psychology -considering a positive subjective, to some extend objective, practice of science- has been restrained and defined as a field advocated to pathological diseases, significantly when the queries for life are emerged together with feelings of desperation and pessimism, conjointly fruitfulness and senseless of life; psychological principles that we implement in therapy and consultation today weren't much appreciated thus far. The preeminence of pathology concluded in a model of individual that is short of positive fundamentals like "hope, wisdom, creativity, future mindedness, courage, spirituality, responsibility, and perseverance" which are furthermore crucial for one 's psychological and physical well-being. Such values were disregarded or characterized as simple variations of credible negative motives. The authors are sketching an infrastructure as well as pointing our gaps in knowledge of positive psychology, and anticipating forthcoming future; expecting communities, societies, and individuals that will thrive through science and the key role of positive psychology. The aim of this study is to excavate principles, inquiries, and definitions of positive psychology to search for means andlor perspectives in generating positive orientation in regard with therapy and consultation, thus reviewing the article: "Positive Psychology, An Introduction" formed by two authors: Martin E. P. Seligman and Mihaly Csikszentmihalyi.
\end{abstract}

Keywords: Positive psychology, orientation, therapy, consulting, pathology, positive fundamentals

\section{Introduction}

Psychologists, since foundation of APA in 1940 have exclusively scanted information on pathology in terms of reaching a life worth of living, but since the inquiry was centered on corporal well-being, they brought up some valuable data in understanding how people can survive or endure adverse conditions. 3 decades of research have shown that an optimistic explanatory style (i. e., attributing negative outcomes to factors that are temporary and specific, rather than to factors that are persistent and pervasive) is associated with better mental and physical health, academic achievement, athletic performance, and performance in many career domains (Hershberger, 2005). However, psychologists have very limited cumulative data on how normal people flourish in peaceful, tranquil conditions. "Psychology has, since World War II, become a science largely about healing..." This almost exclusive attention to pathology neglects the fulfilled individual and thriving community." (Seligman at. al, 2000) On the other hand, the aim of positive psychology is depicted as: "... to begin to catalyze a change in the focus of psychology from preoccupation only with repairing the worst things in life to also building positive qualities. " (Seligman at. al, 2000) At this point, we are presented with individual and group level of positive psychology. For individual level, it's about positive traits as in capacity for love and vocation, courage, forgiveness, originality, future mindedness, spirituality, high talent, and wisdom. At the group level it is about civic virtues and the institutions that move them toward better citizenship. The field of psychology at the subjective level is categorized into three: "in the past, well-being, contentment, and satisfaction, for the future, hope and optimism, in the present, flow and happiness.

"(Seligman at. al, 2000) 


\section{Context of Positive Psychology}

Positive psychology as a scientific study deals with questions like; what makes life worth living? How can we reach the utmost in human potential? How can we make the happy happier? It is an approach and practice of psychology that gives importance not only to the weakness but also to the strength, not only problems of pathology but also mental and psychological well-beings of individuals as well as communities. A positive psychologist according to Martin Seligman and Mihaly Csikszentmihalyi is the one that seeks "to find and nurture genius and talent", and "to make normal life more fulfilling" as the outline of this branch of psychology was first drawn by its founders in 1998.

\section{METHODOLOGY}

\section{"Positive Psychology, An}

Introduction," by Martin E. P. Seligman and Mihaly Csikszentmihalyi was the main source of article review with a perspective of generating positive orientation in therapy or consultation together with secondary sources in reference to articles written on the same issue by psychologists of the same field. More different than other reviews the focus is on orientation of positive psychology in therapy or counseling, moreover the understanding of human potential and using positive emotions to their utmost potential were some other perspectives driven from positive psychology, particularly from the article written for American Psychologist by Martin E. P. Seligman and Mihaly Csikszentmihalyi in January, 2000.

\section{GENERATING POSITIVE ORIENTATION IN THERAPY OR CONSULTATION}

The essence of problem solving has continued to show its vitality in vocational and career psychology. For example, to solve the possible unfit and conflicts in the workplace, individuals have to find three possible solutions. They make themselves adjust to the working environment, and vice versa, they make the working environment more agreeable to their personal needs. (Burwell, R. at. al, 2006) This way of holding matters would be quite helpful in breaching the problems of the clients in counseling as suggested in another article; with a positive orientation and focus on helping clients in a minimum amount of time, the solution-focused therapy can offer an alternative useful model for career counseling intervention. (Burwell, R. at. al, 2006)

What we may infer from given principles and practices of positive psychology is that we have quite little knowledge on positive approach and its advantages in reaching achievement in terms of amplified or nurtured talent of the actual human potential. We infer the very essence of the actual potential of human being through comprehension of positive approach as it is given in the following lines of the article; also referred to as "the science of happiness," positive psychology is striving to be rigorous and evidence based in its endeavor to identify interventions that promote mental health and quality of life. (Hershberger, P. J. at. al, 2005) In our schools we may possibly adopt this approach as it is showing parallel values of enriching individuals, and concentrating on their positive values rather than negativities as they may buffer against mutual understanding, dialogue, tolerance, forgiveness, love, and such universal values which are essential in reaching a universal tranquility.

\section{Using Positive Emotions to Their Fullest Potential}

The article formed by two authors named: Martin E. P. Seligman and Mihaly Csikszentmihalyi present two personal stories that are also involved in the article which come to be the essence of the article in understanding positive psychology. Another perspective is depicted as so; a common perception has been that positive psychology emphasizes the positive at the expense of the negative (Held, 2004; Lazarus, 2003). Regarding the definition, Seligman's story takes place in his garden with his five-year old daughter, Nikki while he was weeding. Her input about learning for not whining, and his being grouch makes him realize that raising Nikki was not about correcting whining, because she did it herself. "I realized that raising Nikki is about taking this marvelous strength she has - I call it "seeing into the soul" - amplifying it, nurturing it, helping her to the storms of life. " (Seligman at. al, 2000) This profound insight for Seligman is an epiphany as it gives a new course to his life in terms of raising children with positive impulses on their talents, like identifying and nurturing their strongest qualities, and helping them find niches in which they can best live out these strengths. 
The story is also a realization of the downsides of the psychology which is likened victimology that the two fundamental missions of psychology "- making the lives of all people better and nurturing genius - were all but forgotten. " (Seligman at. al, 2000)

Mihaly Csikszentmihalyi, like Seligman, realized the need for positive psychology in Europe during World War II: in his story of self-realization. The striking, profound viewpoint is his noticing many adults as successful and self-confident became helpless and dispirited once the war removed their social supports. Yet there were a few who kept their integrity and purpose despite the surrounding chaos. Their serenity was a beacon that kept others from losing hope. (Seligman at. al, 2000) The question that draws him into profound research of reading different branches like philosophy, religion, history etc. is "What sources of strength were these people drawing on?" (Seligman at. al, 2000) The very same question brings him into understanding the need for positive psychology. In his expectation of a science related with human being there should be understanding what is and what could be as to open a pathway to a highway for clinical and behavioral approaches which should stop clinging on those of 10 shelves of psychology related with mere healing, weakness, or damage, and should also stop limiting itself by only fixing what is broken. Treatment related with human being should consider nurturing what is best, work, education, insight, love, growth, and play. This inquiry shouldn't be limited to a mere wishful thinking. In many ways this would be a mark of the movement's success. Also, we use the terms positive and negative as shorthand for describing the two poles of the human condition. (Linley, A. P. at. al, 2006)

\section{Actual Human Potential}

Psychologists come to form the disease model with a struggle of 50 years, perfectionists, on the other hand, discovered human strengths that act as buffers against mental illness as in courage, future mindedness, optimism, impersonal skill, faith, work ethic, hope, honesty, perseverance, and the capacity for flow and insight, to name several. (Seligman at. al, 2000) In a society, the most important sect should be young people, thus the main task of the prevention in our age is to create a science of human strength with a mission of understanding and valuing how to foster these virtues in young people which can be done through positive psychology and positive comparison methodologies. To reach above mentioned task:

"Psychologists need now to call for massive research on human strengths and virtues. Practitioners need to recognize that much of the best work they already do in consulting room is to amplify strengths rather than repair the weaknesses of their clients. Psychologists, working with families, schools, religious communities, and corporations, need to develop climates that foster these strengths. "

They both realized that psychology needs to make people more positive and prevent people from getting mental illnesses altogether as psychology will be reoriented to back its two neglected missions; making normal people stronger and more productive and making high human potential actual (Seligman at. al, 2000). Some of the subheadings which give more detailed information on positive psychology and its ways of practice, given in the article are also worth to mention as they are forming the pillars of positive approach in psychology.

\section{DISCUSSIONS AND LIMITATIONS}

Developmental psychology; cognitive development, developmental therapy etc. have long been conceptualized with counseling by psychologists and practitioners (e. g. Blocher, 1966, 1980; Miller-Tiedeman \& Tiedeman, 1985; Mosher and Sprinthall, 1971; Van Hesteren \& Zingle, 1977) as counselors and therapists see themselves oriented in development while practicing their professions. Haley's family life cycle (1963); Erikson's life-span theory (1973); and Kohlberg's moral development (1981); are three significant examples of orientations in development. In this regard, psychologists must search for links between developmental psychology and positive psychology to assist counselors in helping their clients reach best possible treatment. On the other hand, it can be discussed that positive psychology, as a relatively new branch, may not be the key to this issue yet; it is an open ended field that needs further study which can be considered as a limitation of this paper as well. 


\section{CONCLUSION}

As an approach, generating positive orientation in therapy or consultation we certainly need to train practitioners through a series of assessments and get them ready for the afore-mentioned task of the positive psychology. The ultimate purpose of career counseling is about helping clients become more effective agents in solving problems in their vocational aspects of life. This very same ideology has guided the career development practice and vocational guidance for the past 100 years (Burwell, at. al, 2006). The two authors are eagerly clinging on the idea of reorientation of psychology, as a science, to its two main missions of evaluating normal people and actualizing the high human potential which are great achievements when realized, but how are they to be realized? Who are to realize them? Limiting it to psychologists might lead it to a dead end. On the other hand if we can manage to implement principles of positive psychology in therapy or consultation we may achieve more fruitful, desired results of nurturing what is best, helping the happy to become happier etc. which are also expected results of positive psychology when applied correctly by practitioners, psychologists and consultants.

\section{REFERENCES}

Blocher, D. (1966) Developmental counseling. New York: Roland.

Blocher, D. (1980) Some implications of recent research in social and developmental psychology for counseling practice. Personnel and Guidance Journal, 58, 334-336

Burwell, R. \& Chen C. P. (2006). Theory and Practice, Applying the principles and techniques of solution-focused therapy to career counseling.

Erikson, E. (1950) Childhood and society. New York: Norton.

Haley, J. (1973) Strategies of psychotherapy. New York: Grune \& Stratton.

Held, B. S. (2004). The negative side of positive psychology. Journal of Humanistic Psychology, 44, 9-46.

Hershberger, P. J. (2005). Prescribing Happiness: Positive Psychology and Family Medicine.

Kohlberg, L. (1981) The philosophy of moral development. San Francisco: Harper \& Row.

Linley, A. P. \& Stephen J. \& Harrington, S. \& Wood, M. A. The Journal of Positive Psychology, Positive psychology: Past, present, and (possible) future.

Miller-Tiedeman, A., \& Tiedeman, D. (1985) Educating to advance human career during the 1990's and beyond. Vocational Guidance Quarterly, 34, 15-30.

Mosher, R., \& Sprinthall, N. (1971) Psychological education: A means to promote personal developmental during adolescence. The Counseling Psychologist, 2 (4), 3-82.

Seligman, M. E. P. \& Csikszentmihalyi M. (2000) American Psychologist (Positive Psychology, an Introduction).

Van Hesteren, F. \& Zingle, H. (1977) On stepping into the same river twice: The future of school counseling. Canadian Counselor, 11, 105-116. 